
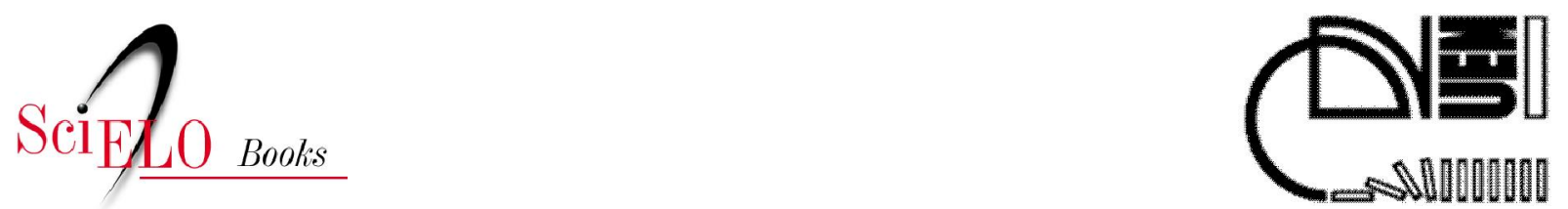

\title{
1 A emancipação política do Paraná
}

\author{
Angelo Priori \\ Luciana Regina Pomari \\ Silvia Maria Amâncio \\ Veronica Karina Ipólito
}

PRIORI, A., et al. História do Paraná: séculos XIX e XX [online]. Maringá: Eduem, 2012. A emancipação política do Paraná. pp. 15-22. ISBN 978-85-7628-587-8. Available from SciELO Books $<\underline{\text { http://books.scielo.org }>\text {. }}$

\section{(1) (1) @()}

All the contents of this chapter, except where otherwise noted, is licensed under a Creative Commons Attribution-Non Commercial-ShareAlike 3.0 Unported.

Todo o conteúdo deste capítulo, exceto quando houver ressalva, é publicado sob a licença Creative Commons Atribuição Uso Não Comercial - Partilha nos Mesmos Termos 3.0 Não adaptada.

Todo el contenido de este capítulo, excepto donde se indique lo contrario, está bajo licencia de la licencia Creative Commons Reconocimento-NoComercial-CompartirIgual 3.0 Unported. 


\section{1}

\section{A Emancipação Política do Paraná}

O que é emancipação? Em linhas gerais, esse conceito refere-se à liberdade ou independência alcançada em relação ao domínio de outro. Para esclarecer essa definição, podemos utilizar dois exemplos: em 1822 o Brasil 'emancipou-se' de Portugal e em 1888 os escravos brasileiros foram 'emancipados'. Em ambos os casos, o conceito de emancipação designa a liberdade em relação a uma tutela exercida há tempos. Se o conceito de emancipação está intimamente ligado à conquista de autonomia, por que estudar a emancipação política do Paraná? Este território nem sempre foi autônomo? Na realidade, até 1853, não existia o Paraná. O território que hoje conhecemos como paranaense pertencia a São Paulo. Que tal conhecer essa parte da história do Estado?

No final do século XVI e início do XVII as buscas por metais preciosos tiveram êxito na Baía de Paranaguá. Por ter sido a primeira região do Brasil a apresentar sinais de ouro, o território passou a receber povoadores, especialmente paulistas. A produção aurífera foi responsável, portanto, em 1660, pela transformação de Paranaguá em Capitania. Nesse mesmo contexto houve a fundação de Curitiba.

No entanto, a descoberta e ouro na região Centro-oeste do Brasil desviou os olhos da Coroa Portuguesa do território paranaense. Assim, 
em 1710, conforme Severino (2009, p. 20), foi fundada a Capitania Geral de São Paulo, que abrangia os territórios das capitanias de Paranaguá, São Vicente, Santo Amaro, Minas Gerais, Goiás, Mato Grosso e se estendia para o Sul da colônia. Nesse momento, portanto, o território paranaense passou a estar sob tutela paulista, com a denominação de $5^{\text {a }}$ Comarca de São Paulo, com sede em Paranaguá.

Durante a primeira metade do século XVIII o território da capitania paulista sofreu desmembramentos: Minas Gerais, Goiás, Santa Catarina, Rio Grande de São Pedro (atual Rio Grande do Sul) e Mato Grosso emanciparam-se. Em 1748, a própria Capitania de São Paulo perdeu sua autonomia, ficando subordinada à comarca do Rio de Janeiro. Em 1763, porém, o Rio de Janeiro tornou-se capital do Brasil. Com isso, houve uma nova re-estruturação política e São Paulo voltou a ser uma capitania autônoma em 1765, possuindo como territórios os atuais Estados paulista e paranaense (SEVERINO, 2009, p. 20).

Enquanto o território paranaense era Comarca de São Paulo, não havia uma estrutura competente para as exigências administrativas da região. A segurança era péssima, não havia escolas, nem professores suficientes para a população. A justiça era mal aplicada e lenta. Os serviços públicos eram precários. Verbas eram desviadas e, além disso, a Comarca sofria com pesados tributos pagos tanto para o Império, quanto para a província de São Paulo.

Essa conjuntura gerava grande insatisfação. Assim, parte da população da Comarca começou lutar por sua liberdade políticoadministrativa. Em 1811, tendo em vista a presença da Família Real no Brasil, ocorreu a primeira tentativa de emancipação política do território paranaense. Pedro Joaquim de Sá, representante da Câmara de Paranaguá, foi a pessoa responsável para apresentar a D. João VI as possíveis vantagens com a separação do Paraná da província de São Paulo.

Contudo, esse trabalho não surtiu efeito. Acreditava-se que a $5^{\text {a }}$ Comarca não possuía condições financeiras e sociais para ser autônoma. Por isso, era imprescindível a proteção desenvolvida por São Paulo. O 
que o Príncipe Regente D. João VI fez, durante sua estadia no Brasil, foi transferir, em 1812, a sede da $5^{\mathrm{a}}$ Comarca de Paranaguá para Curitiba.

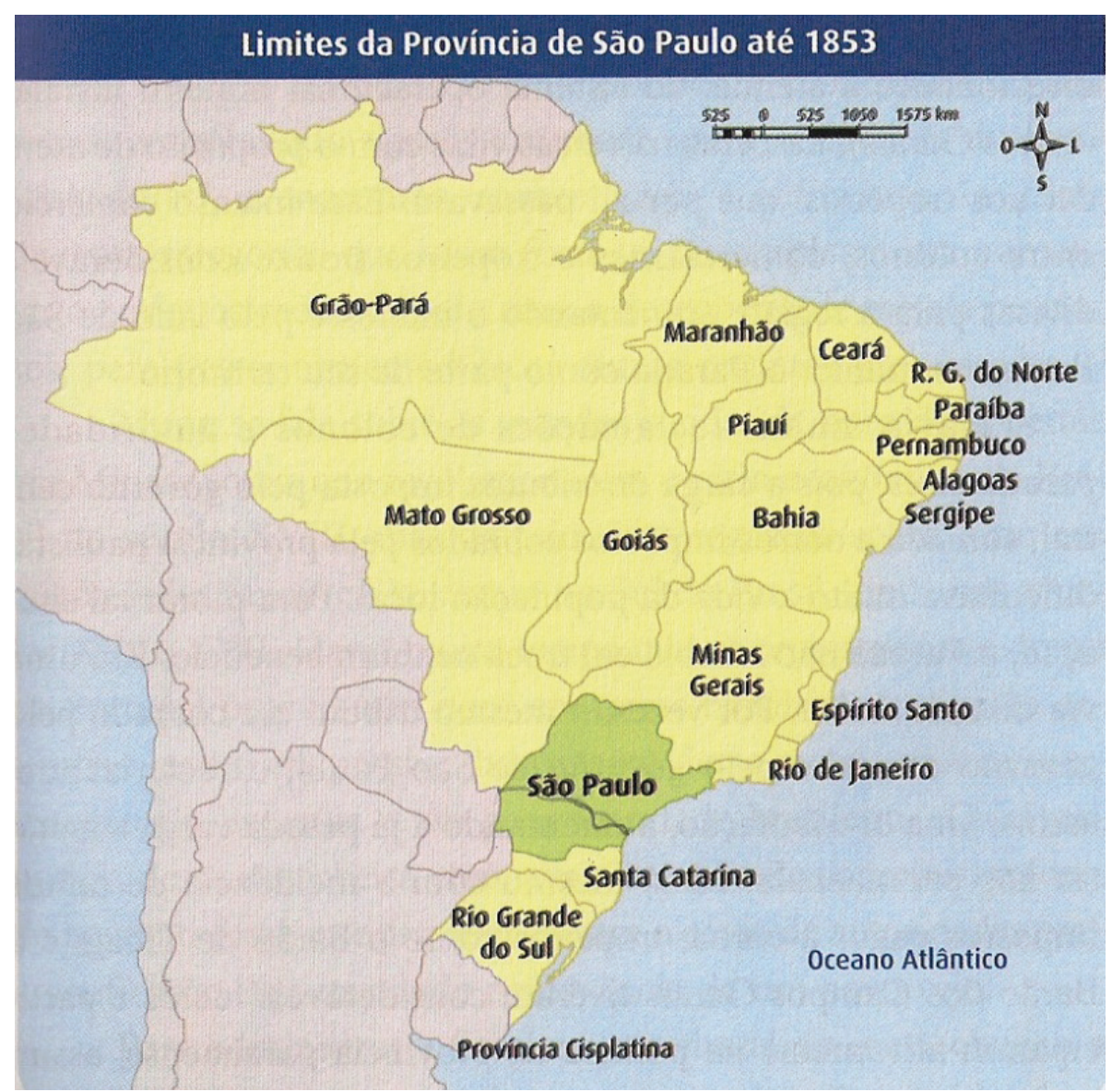

Figura 1: Mapa do Brasil (1853)

Fonte: Campinas (2005, p. 137).

Outra tentativa concreta que visava à conquista da autonomia política do Paraná ocorreu somente em 1821, quando os defensores da emancipação iniciaram um movimento que ficou conhecido como 'Conjura Separatista'. De acordo com Campinas (2005), o personagem principal desse movimento foi o Capitão Floriano Bento Viana que, aproveitando- 
se do ato de juramento à constituição do Reino Unido de Portugal, Brasil e Algarves, apresentou a vontade de emancipação do povo paranaense frente às autoridades paulistas. $\mathrm{O}$ juiz-de-fora presente em Curitiba para tal evento, Antonio Azevedo Melo e Carvalho, foi veemente ao pronunciar que ainda não era tempo da emancipação, pois os interesses paulistas

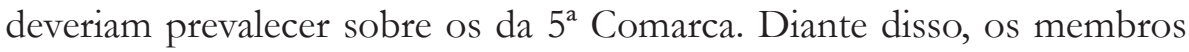
da Conjura se intimidaram, fazendo com que a ação não prosperasse. Inclusive, foi aberto um inquérito para investigar os responsáveis pelo movimento e alguns de seus líderes foram perseguidos.

Apesar desse fracasso, os pedidos de emancipação continuaram, sem, contudo, produzir frutos. Os insucessos com as tentativas de separação político-administrativa da $5^{\mathrm{a}}$ Comarca não desanimaram os moradores da região (WACHOWICZ, 1972). Ideias de emancipação surgiram nas câmaras de vereadores de Antonina, Castro, Curitiba, Morretes, Paranaguá e Vila do Príncipe (Lapa).

Na primeira metade do século XIX, a $5^{a}$ Comarca de São Paulo sofreu importantes mudanças econômicas: a produção do mate e da madeira despontou no mercado do Prata e no Chile, ultrapassando a importância econômica do comércio de gado que havia entrado em decadência. Essa intensa atividade econômica aumentava, entre a elite paranaense, o desejo pela separação de São Paulo.

Durante o Período Regencial no Brasil (1831-1840), surgiram rebeliões em várias partes do Império. Uma das revoltas mais intensas aconteceu no Rio Grande Sul, conhecida como Revolta Farroupilha (18351845), desencadeada pelo descaso das autoridades imperiais em relação à economia de criação de gado e de produção de charque na região Sul. Temendo que as forças revolucionárias encontrassem adesão no Paraná, a província de São Paulo buscou apoio em Curitiba, prometendo, em troca, a emancipação da Comarca. Com essa promessa, Curitiba passou a cooperar com o Governo Central, lutando contra os revolucionários.

1 Campinas (2005) destaca que o capitão Bento Viana foi poupado das punições pelo fato de ter sido considerado fiel à Coroa Portuguesa. 
O apoio eficaz de Curitiba agradou o presidente da província de São Paulo, Barão de Monte Alegre, que solicitou ao governo imperial, em 1842, a emancipação da Comarca, indicando Curitiba para capital da nova Província, por sua localização geográfica. Essa situação incomodou a Câmara de Paranaguá que requeria para si o papel de capital, justamente por sua importância histórica. Essa disputa entre Paranaguá e Curitiba adiou a emancipação.

Em 1843 aconteceu outra tentativa. Como perder a comarca paranaense seria desastroso, economicamente, para São Paulo, os deputados paulistas tentaram atrasar as discussões sobre a emancipação, criando um projeto para a formação da província de Sapucaí, que seria separada de Minas Gerais. Nesse contexto, a emancipação paranaense, mais uma vez, foi adiada.

Só em 1850 o assunto foi considerado pelo Império, pois, nessa época, surgiu a preocupação com possíveis invasões dos países vizinhos. Dessa forma, regiões de fronteira passaram a ser mais bem estruturadas, com vistas a evitar qualquer invasão estrangeira. Essa nova política possibilitou a criação da província do Amazonas, trazendo, novamente, à tona, a questão da emancipação da $5^{\text {a }}$ Comarca de São Paulo.

Como não possuíam interesse na separação política entre Paraná e São Paulo, os deputados paulistas buscaram tumultuar o processo de emancipação da $5^{\text {a }}$ Comarca, desmembrando seus distritos em dez unidades, reduzindo, dessa forma, o território pertencente à Comarca de Curitiba. Assim, em 1852, Curitiba passou de $5^{\text {a }}$ Comarca para $10^{a}$ Comarca da Província de São Paulo, por meio da Lei 437:

O bacharel formado Hypolito Soares de Souza, vicepresidente da Província de São Paulo, faço saber a todos os seus habitantes que a Assembléia Legislativa Provincial decretou e eu sancionei a lei seguinte:

Art. $1^{\circ}$ - As comarcas da Província ficam elevadas a dez, e sua denominação e divisão seguinte:

[...] 
$10^{\circ}$ - Comarca de Curitiba compreendendo esta cidade, Paranaguá, Príncipe, Antonina, Morretes, Guaratuba e Castro.

Mando, portanto, a todas as autoridades, a quem o conhecimento e execução da referida Lei pertencer, que a cumpram e façam cumprir tão inteiramente, com nela se contém (PARANÁ, 2003, p.15).

Nesse contexto, Minas Gerais e Bahia passaram a apoiar a causa paranaense, interessadas na possível diminuição da importância política de São Paulo. Assim, em 2 de Agosto de 1853, o projeto de emancipação da comarca do Paraná foi aprovado e, em 29 do mesmo mês, sob Lei no 704 sancionada por D. Pedro II, foi criada a província paranaense:

Dom Pedro II, por graça de Deus e unânime aclamação dos povos, Imperador Constitucional e Defensor Perpétuo do Brasil: Fazemos saber a todos os nossos súditos que a Assembléia Geral Legislativa decretou e nós queremos a lei seguinte:

Art. $1^{\circ}$ - A Comarca de Curitiba, na Província de São Paulo, fica elevada à categoria de Província do Paraná. A sua extensão e limites serão os mesmos da referida Comarca.

Art. $2^{\circ}$ - A nova Província terá por capital a cidade de Curitiba, enquanto a Assembléia respectiva não Decretar o contrário.

Art. $3^{\circ}$ - A Província do Paraná terá um senador e um deputado à Assembléia Geral; sua Assembléia Provincial constará 20 membros.

Art. $4^{\circ}$ - O Governo fica autorizado para criar na mesma Província as estações fiscais indispensáveis gerais, submetendo depois o que houver determinado ao conhecimento da Assembléia Geral para definitiva aprovação.

Art. $5^{\circ}$ - Ficam revogadas as disposições em contrário.

Mandamos, portanto, a todas as autoridades a quem o conhecimento desta lei pertencer, que a cumpram e façam cumprir e guardar tão inteiramente como nela se contém. O Secretário de Estado dos Negócios do Império a faça imprimir, publicar e correr. Dada no palácio do Rio de Janeiro, aos vinte e nove de Agosto de mil oitocentos e cinqüenta e três, trigésimo segundo da Independência e do Império (CAMARGO, 2004, p. 160). 
Em 19 de dezembro de 1853 aconteceu a instalação solene da nova província, tomando posse o primeiro presidente, Zacarias de Góes e Vasconcellos.

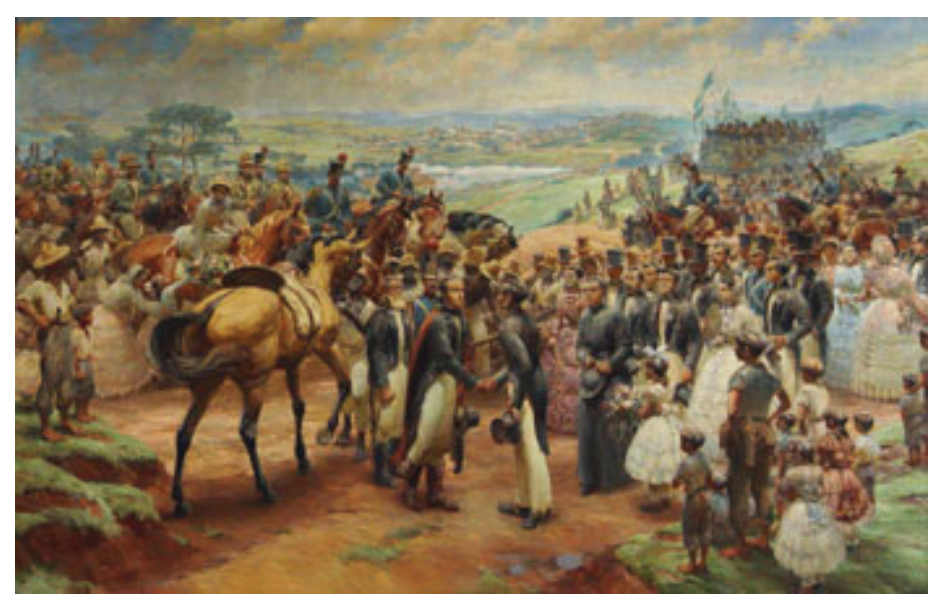

Figura 2: 1853 - Chegada do Conselheiro Zacarias, em Curitiba, para a instalação da Província do Paraná Fonte: Paraná (2012).

Zacarias de Góes e Vasconcellos era um político experiente: foi governador das províncias de Piauí e Sergipe e, também, exerceu os cargos de deputado e de ministro da Marinha. Por isso, suas atitudes foram fundamentais para o desenvolvimento da província do Paraná. Como presidente, efetuou estudos sobre as possibilidades de construção de estradas que ligassem Curitiba até o litoral, medida de grande importância econômica para a nova província, pois possibilitaria o transporte de mercadorias de uma região para a outra com maior eficácia. Outra medida importante tomada por Vasconcellos foi aplicar, na instrução pública primária do Paraná, investimento que, além de contribuir para a qualificação de mão de obra na província, também possibilitaria um 'abrasileiramento' dos estrangeiros que chegavam às terras paranaenses (CAMPINAS, 2005). 
A nova província recebeu o nome de Paraná, denominação que vem da língua Guarani e significa 'semelhante ao mar', por ser o nome do maior curso d'água do território paranaense, o Rio Paraná (PARANÁ, 2012). O Presidente Zacarias de Góes e Vasconcellos manteve Curitiba como Capital da Província do Paraná e a dividiu em três comarcas: Curitiba, Paranaguá e Castro. Nesse momento, o Paraná tinha em seu território duas cidades - Curitiba e Paranaguá -, sete vilas - Guaratuba, Antonina, Morretes, São José dos Pinhais, Príncipe (Lapa), Castro e Guarapuava -, seis freguesias - Campo Largo, Palmeira, Ponta Grossa, Jaguariaíva, Tibagi e Rio Negro - e cinco capelas curadas - Guaraqueçaba, Iguaçu, Tindiquera (atual Araucária), Votuverava (Rio Branco) e Palmas. A população era de aproximadamente 62.258 habitantes. A vida econômica era baseada na pecuária, muares, agricultura de subsistência, comércio, indústria extrativa de erva-mate e indústria de transformação incipiente (CAMPINAS, 2005).

\section{Referências}

CAMARGO, João Borba. História do Paraná: 1500-1889. Maringá: Bertoni, 2004.

CAMPINAS, Ricardo da Costa. A emancipação política e as alternativas de poder. In: SCORTEGAGNA, Adalberto; REZENDE, Cláudio Joaquim; TRICHES, Rita Inocêncio (Org.). Paraná, espaço e memória: diversos olhares histórico-geográficos. Curitiba: Bagozzi, 2005. p. 130-157.

PARANÁ. Páginas escolbidas: história. Curitiba: Assembleia Legislativa do Paraná, 2003. Edição alusiva aos 150 anos da Criação Política do Paraná.

PARANÁ. Secretaria do Estado da Cultura. Origem do nome e criação da Província. Disponível em: <http://www.cidadao.pr.gov.br/modules/conteudo/conteudo. php?conteudo=72>. Acesso em: 18 jan. 2012.

SEVERINO, Caroline Silva. A dinâmica do poder e da autoridade na Comarca de Paranaguá e Curitiba (1765-1822). 2009. 131 f. Dissertação (Mestrado em História) - Universidade Estadual Paulista 'Júlio de Mesquita Filho', Franca, 2009. Disponível em: <http://www. franca.unesp.br/poshistoria/caroline.pdf>. Acesso em: 18 jan. 2012.

WACHOWICZ, Ruy Christovam. História do Paraná. Curitiba: Gráfica Vicentina, 1972. 